\title{
An Empirical Study of Second Order Rotatable Designs under Tri-Diagonal Correlated Structure of Errors using Incomplete Block Designs
}

\author{
K. Rajyalakshmi* and B. Re. Victorbabu \\ Department of Statistics, Acharya Nagarjuna University, Guntur -522510, \\ India \\ *Corresponding Author: rajyalakshmi_kottapalli@yahoo.com
}

Received: $26^{\text {th }}$ April 2014 / Revised: $5^{\text {th }}$ November 2015 / Accepted: $31^{\text {st }}$ January 2016 CIAppStat-SL2016

\begin{abstract}
In this paper, an empirical study of second order rotatable designs under tri-diagonal correlated structure of errors using incomplete block designs like pairwise balanced designs (PBD) and symmetrical unequal block arrangements (SUBA) with two unequal block sizes are suggested. Further we study the variance function of the estimated response for different values of tri-diagonal correlated coefficient ( $\rho$ ) and distance from center (d) for $6 \leq v \leq 15$ ( $v$ number of factors)).
\end{abstract}

Keywords: Second order rotatable designs (SORD), tri-diagonal correlated errors.

\section{Introduction}

Box and Hunter (1957) introduced rotatable designs for the exploration of response surface designs. Das and Narasimham (1962) constructed rotatable designs through balanced incomplete block designs (BIBD). Raghavarao (1962) constructed symmetrical unequal block arrangements (SUBA) with two unequal block sizes. Raghavarao (1963) constructed second order rotatable designs (SORD) using incomplete block designs. Tyagi (1964) constructed SORD using pairwise balanced designs (PBD). Panda and Das (1994) studied first order rotatable designs with correlated errors. Das (1997, 1999, 2003) introduced and studied robust second order rotatable designs (RSORD). Rajyalakshmi and Victorbabu (2014a) suggested an study of SORD under tri-diagonal correlated structure of errors empirical using central composite designs. Rajyalakshmi and 
Victorbabu (2014b) suggested an empirical study of SORD under tridiagonal correlated structure of errors using BIBD.

In this paper following the work of Das (2003), an empirical study of SORD under tri-diagonal correlated structure of errors using incomplete block designs like PBD and SUBA with two unequal block sizes are suggested. Further we study the variance function of the estimated response for different values of tri-diagonal correlated coefficient $(\rho)$ and also obtain the distance from center (d) for " $v=8$ factor".

\section{Conditions for SORD under tri-diagonal correlated structure of errors (cf. Das (2003))}

A Second order response surface design $\mathrm{D}=\left(\left(\mathrm{x}_{\mathrm{iu}}\right)\right)$ for fitting,

$$
\begin{aligned}
\mathrm{Y}_{\mathrm{u}}(\mathrm{x}) & =\mathrm{b}_{0}+\sum_{\mathrm{i}=1}^{\mathrm{v}} \mathrm{b}_{\mathrm{i}} \mathrm{x}_{\mathrm{iu}}+\sum_{\mathrm{i}=1}^{\mathrm{v}} \mathrm{b}_{\mathrm{ii}} \mathrm{x}_{\mathrm{iu}}^{2}+\sum_{\mathrm{i} \leq \mathrm{j}}^{\mathrm{v}} \sum \mathrm{b}_{\mathrm{ij}} \mathrm{x}_{\mathrm{iuju}} \\
& +\varepsilon_{\mathrm{u}}
\end{aligned}
$$

where $\mathrm{x}_{\mathrm{iu}}$ denotes the level of the $\mathrm{i}^{\text {th }}$ factor $(\mathrm{i}=1,2, \ldots, \mathrm{v})$ in the $\mathrm{u}$-th run $(\mathrm{u}=1,2, \ldots, \mathrm{N}=2 \mathrm{n})$ of the experiment, $\mathrm{e}_{\mathrm{u}}$ 's are correlated random errors is said to be a SORD under tri-diagonal correlation structure of errors, if the variance of the estimated response of $\widehat{Y}_{u}$ from the fitted surface is only a function of the distance, $\left(\mathrm{d}^{2}=\sum \mathrm{x}_{\mathrm{i}}^{2}\right)$ of the point $\left(\mathrm{x}_{1 \mathrm{u}}, \mathrm{x}_{2 \mathrm{u}}, \ldots, \mathrm{x}_{\mathrm{vu}}\right)$ from the origin (centre) of the design. Such a spherical variance function for estimation of responses in the second order response surface is achieved if the design points satisfy the following conditions (cf. Das, 1997, 2003, 2004).

The necessary and sufficient conditions for second order rotatability under the tri-diagonal correlated variance - covariance structure in the model (1) are

$$
\begin{aligned}
& \begin{array}{l}
\text { (i) } \sum_{u=1}^{2 n} x_{j u}=0, \\
\leq v ; \\
\text { (iii) } \sum_{u=1}^{2 n} x_{i u} x_{j u}-\rho\left\{\sum_{u=1}^{n} x_{i(n+u)} x_{j u}+\sum_{u=1}^{n} x_{i u} x_{j(n+u)} x_{j u} x_{l u}=0,1 \leq j\right. \\
\quad 1 \leq i \neq j \leq v ; \\
\text { (iv) } \sum_{u=1}^{2 n} x_{i u}^{2} x_{j u}-\rho\left\{\sum_{u=1}^{n} x_{i(n+u)}^{2} x_{j u}+\sum_{u=1}^{n} x_{i u}^{2} x_{j(n+u)}\right\}=0, \quad 1 \leq i, j \leq v ;
\end{array}
\end{aligned}
$$


An Empirical Study of Second Order Rotatable Designs

(v) $\sum_{u=1}^{2 n} x_{i u} x_{j u} x_{l u}-\rho\left\{\sum_{u=1}^{n} x_{i(n+u)} x_{j(n+u)} x_{l u}+\sum_{u=1}^{n} x_{i u} x_{j u} x_{l(n+u)}\right\}=0$,

$$
1 \leq \mathrm{i}<j, l \leq v
$$

(vi) $\sum_{u=1}^{2 n} x_{i u}^{2} x_{j u} x_{l u}-\rho\left\{\sum_{u=1}^{n} x_{i(n+u)}^{2} x_{j u} x_{l u}+\sum_{u=1}^{n} x_{i u}^{2} x_{j(n+u)} x_{l(n+u)}\right\}=0$,

$$
1 \leq \mathrm{i}, \mathrm{j}<l \leq v ;(\mathrm{j}, \mathrm{l}) \neq(\mathrm{i}, \mathrm{i})
$$

(vii) $\sum_{u=1}^{2 n} x_{i u} x_{j u} x_{l u} x_{t u}$

$$
\begin{aligned}
& -\rho\left\{\sum_{u=1}^{n} x_{i(n+u)} x_{j(n+u)} x_{l u} x_{t u}+\sum_{u=1}^{n} x_{i u} x_{j u} x_{l(n+u)} x_{t(n+u)}\right\} \\
& =0, \\
& 1 \leq i, l<j, t \leq v ;(i, j) \neq(l, t)
\end{aligned}
$$

$$
\sum_{\substack{u=1 \\=2 n}}^{2 n} x_{i u}^{2}=\text { constant }
$$

$\sum_{u=1}^{2 n} x_{i u}^{4}=$ constant $=6 n \lambda_{4}$

for all $\mathrm{i}$

$\sum_{u=1}^{2 n} x_{i u}^{2} x_{j u}^{2}=$ constant $=2 n \lambda_{4}$, for all $i$

$\neq \mathrm{j}$

Using (3), (4) and (5) the design parameters of the tri-diagonal correlated structure are as follows:

$$
\begin{aligned}
& (1-\rho)\left\{\sigma^{2}\left(1-\rho^{2}\right)\right\}^{-1} \sum_{u=1}^{2 n} x_{j u}^{2} \\
& =\frac{2 n \lambda_{2}(1-\rho)}{\sigma^{2}\left(1-\rho^{2}\right)} \\
& \left\{\sigma^{2}\left(1-\rho^{2}\right)\right\}^{-1}\left[\sum_{u=1}^{2 n} x_{i u}^{2}-2 \rho \sum_{u=1}^{n} x_{i u} x_{i}(n+u)\right]=\frac{2 n \lambda_{2}}{\sigma^{2}\left(1-\rho^{2}\right)}, 1 \leq i \\
& \leq v
\end{aligned}
$$




$$
\begin{aligned}
\left\{\sigma^{2}\left(1-\rho^{2}\right)\right\}^{-1} & {\left[\sum_{u=1}^{2 n} x_{i u}^{4}-2 \rho \sum_{u=1}^{n} x_{i u}^{2} x_{i(n+u)}^{2}\right]=3\left(\frac{2 n \lambda_{4}}{\sigma^{2}\left(1-\rho^{2}\right)}\right) ; 1 \leq i } \\
& \leq v \\
\left\{\sigma^{2}\left(1-\rho^{2}\right)\right\}^{-1} & {\left[\sum_{u=1}^{2 n} x_{i u}^{2} x_{j u}^{2}-\rho\left[\sum_{u=1}^{n} x_{i(n+u)}^{2} x_{j u}^{2}+\sum_{u=1}^{n} x_{i u}^{2} x_{j(n+u)}^{2}\right]\right] } \\
& =\frac{2 n \lambda_{4}}{\sigma^{2}\left(1-\rho^{2}\right)} ; \\
\left\{\sigma^{2}\left(1-\rho^{2}\right)\right\}^{-1} & {\left[\sum_{u=1}^{2 n} x_{i u}^{2} x_{j u}^{2}-2 \rho \sum_{u=1}^{n} x_{i u} x_{j u} x_{i(n+u)} x_{j(n+u)}\right]=\frac{2 n \lambda_{4}}{\sigma^{2}\left(1-\rho^{2}\right)} } \\
& \leq i<j \\
& \leq v
\end{aligned}
$$

From (8), (9) and (10),

$$
\begin{aligned}
\left\{\sigma^{2}\left(1-\rho^{2}\right)\right\}^{-1} & {\left[\sum_{u=1}^{2 n} x_{i u}^{4}-2 \rho \sum_{u=1}^{n} x_{i u}^{2} x_{i(n+u)}^{2}\right] } \\
& =2\left(\{ \sigma ^ { 2 } ( 1 - \rho ^ { 2 } ) \} ^ { - 1 } \left[\sum_{u=1}^{2 n} x_{i u}^{2} x_{j u}^{2}\right.\right. \\
& \left.\left.-2 \rho \sum_{u=1}^{n} x_{i u} x_{j u} x_{i(n+u)} x_{j(n+u)}\right]\right) \\
& +\left\{\sigma^{2}\left(1-\rho^{2}\right)\right\}^{-1}\left[\sum_{u=1}^{2 n} x_{i u}^{2} x_{j u}^{2}\right. \\
& \left.-\rho\left[\sum_{u=1}^{n} x_{i(n+u)}^{2} x_{j u}^{2}+\sum_{u=1}^{n} x_{i u}^{2} x_{j(n+u)}^{2}\right]\right]
\end{aligned}
$$

which implies to $3\left(\frac{2 \mathrm{n} \lambda_{4}}{\sigma^{2}\left(1-\rho^{2}\right)}\right)$

$$
\begin{aligned}
& =2\left(\left(\frac{2 \mathrm{n} \lambda_{4}}{\sigma^{2}\left(1-\rho^{2}\right)}\right)\right. \\
& +\left(\frac{2 \mathrm{n} \lambda_{4}}{\sigma^{2}\left(1-\rho^{2}\right)}\right)
\end{aligned}
$$

where $\mathrm{N}=2 \mathrm{n}$. 
The variances and covariances of the estimated parameters under the tri-diagonal correlated structure of errors are as follows:

$$
\begin{aligned}
& \mathrm{v}\left(\hat{\mathrm{b}}_{0}\right)=\frac{\lambda_{4}(\mathrm{v}+2)(1+\rho) \sigma^{2}}{2 \mathrm{n}\left[\lambda_{4}(\mathrm{v}+2)-\mathrm{v} \lambda_{2}^{2}(1-\rho)\right]} \\
& \mathrm{V}\left(\hat{\mathrm{b}}_{\mathrm{i}}\right)=\frac{\sigma^{2}\left(1-\rho^{2}\right)}{2 \mathrm{n} \lambda_{2}} \\
& \mathrm{~V}\left(\hat{\mathrm{b}}_{\mathrm{ij}}\right)=\frac{\sigma^{2}\left(1-\rho^{2}\right)}{2 \mathrm{n} \lambda_{4}} \\
& \mathrm{~V}\left(\hat{\mathrm{b}}_{\mathrm{ii}}\right)=\frac{\sigma^{2}\left(1-\rho^{2}\right)\left[\lambda_{4}(\mathrm{v}+1)-(\mathrm{v}-1) \lambda_{2}^{2}(1-\rho)\right]}{2(2 \mathrm{n}) \lambda_{4}\left[\lambda_{4}(\mathrm{v}+2)-\mathrm{v} \lambda_{2}^{2}(1-\rho)\right]} \\
& \operatorname{Cov}\left(\hat{\mathrm{b}}_{0}, \hat{\mathrm{b}}_{\mathrm{ii}}\right)=\frac{-\lambda_{2} \sigma^{2}\left(1-\rho^{2}\right)}{2 \mathrm{n}\left[\lambda_{4}(\mathrm{v}+2)-\mathrm{v} \lambda_{2}^{2}(1-\rho)\right]} \\
& =\frac{\sigma^{2}\left(1-\rho^{2}\right)\left[\lambda_{2}^{2}(1-\rho)-\lambda_{4}\right]}{2(2 \mathrm{n}) \lambda_{4}\left[\lambda_{4}(\mathrm{v}+2)-\mathrm{v} \lambda_{2}^{2}(1-\rho)\right]} \\
& \text { and other covariances are zero. }
\end{aligned}
$$$$
\operatorname{Cov}\left(\hat{\mathrm{b}}_{\mathrm{ii}}, \hat{\mathrm{b}}_{\mathrm{jj}}\right)
$$

An inspection of the variance shows that a necessary condition for the existence of a non-singular second order design is

$$
\begin{aligned}
& \frac{\lambda_{4}}{\lambda_{2}^{2}} \\
& >\frac{\mathrm{v}(1-\rho)}{\mathrm{v}+2} \text { (Non } \\
& - \text { singularity condition) }
\end{aligned}
$$

The variance of the response $\widehat{Y}_{0}$ at any point estimated through the surface comes out as,

$$
\mathrm{V}\left(\widehat{\mathrm{Y}}_{\mathrm{u}}\right)=\mathrm{V}\left(\hat{\mathrm{b}}_{0}\right)+\mathrm{d}^{2}\left[\mathrm{~V}\left(\hat{\mathrm{b}}_{\mathrm{i}}\right)+2 \operatorname{cov}\left(\hat{\mathrm{b}}_{0}, \hat{\mathrm{b}}_{\mathrm{ii}}\right)\right]+\mathrm{d}^{4} \mathrm{~V}\left(\hat{\mathrm{b}}_{\mathrm{ii}}\right) .
$$

Hence the variance of estimate of $\widehat{Y}_{0}$ becomes,

$$
\begin{aligned}
& \mathrm{V}\left(\widehat{\mathrm{Y}}_{\mathrm{u}}\right)=\frac{\lambda_{4}(\mathrm{v}+2)(1+\rho) \sigma^{2}}{2 \mathrm{n}\left[\lambda_{4}(\mathrm{v}+2)-\mathrm{v} \lambda_{2}^{2}(1-\rho)\right]} \\
& +\left[\frac{\sigma^{2}\left(1-\rho^{2}\right)}{2 \mathrm{n} \lambda_{2}}+2\left(\frac{-\lambda_{2} \sigma^{2}\left(1-\rho^{2}\right)}{2 \mathrm{n}\left[\lambda_{4}(\mathrm{v}+2)-\mathrm{v} \lambda_{2}^{2}(1-\rho)\right]}\right)\right] \mathrm{d}^{2} \\
& +\frac{\sigma^{2}\left(1-\rho^{2}\right)\left[\lambda_{4}(\mathrm{v}+1)-(\mathrm{v}-1) \lambda_{2}^{2}(1-\rho)\right]}{2(2 \mathrm{n}) \lambda_{4}\left[\lambda_{4}(\mathrm{v}+2)-\mathrm{v} \lambda_{2}^{2}(1-\rho)\right]} \mathrm{d}^{4}
\end{aligned}
$$




\section{An empirical study on SORD under tri-diagonal correlated structure of errors using PBD}

Following Tyagi (1964) and Das (2003) methods of constructions of SORD and RSORD, an empirical study on SORD under tri-diagonal correlated structure of errors using PBD is studied.

Let $\left(v, b, r, k_{1}, k_{2} \ldots k_{p}, \lambda\right)$ is an equi-replicated PBD and $k=\sup \left[k_{1}\right.$, $\left.\mathrm{k}_{2}, \ldots, \mathrm{k}_{\mathrm{p}}\right] .2^{\mathrm{t}(\mathrm{k})}$ denotes a resolution $\mathrm{V}$ fractional factorial of $2^{\mathrm{k}}$ in \pm 1 levels, in which no interaction with less than five factors is confounded and $\mathrm{n}_{0}$ denote the number of central points.

Consider a SORD using PBD having ' $n$ ' non-central design points. The set of ' $n$ '-non central design points are extended to $2 n$ design points by adding ' $n$ ' $\left(n_{0}=n\right)$ central points just below or above the ' $n$ ' non-central design points. Hence $2 \mathrm{n}$ be the total number of design points $(\mathrm{N})$ of SORD under tri-diagonal correlated structure of errors using PBD.

\section{Case (i): when $\mathbf{r}<\mathbf{3 \lambda}$}

The design points, [1-(v, b, r, $\left.\left.\mathrm{k}_{1}, \mathrm{k}_{2}, \ldots, \mathrm{k}_{\mathrm{p}}, \lambda\right)\right] 2^{\mathrm{t}(\mathrm{k})} \cup(\mathrm{a}, 0,0, \ldots, 0) 2^{1} \cup\left(\mathrm{n}_{0}\right)$, will give a v-dimensional SORD under tri-diagonal correlated structure of errors in $\mathrm{N}\left(=2 \mathrm{n}, \mathrm{n}=\mathrm{b} 2^{\mathrm{t}(\mathrm{k})}+2 \mathrm{v}\right)$ design points, with $\mathrm{a}^{4}=(3 \lambda-\mathrm{r}) 2^{\mathrm{t}(\mathrm{k})-1}$.

Proof: For the design points generated from the PBD, simple symmetry conditions are true. Further we have the reduced conditions,

$$
\begin{aligned}
& \sum_{u=1}^{2 n} x_{i u}^{2}=r 2^{t(k)}+2 a^{2}=\text { constant } \\
& =2 n \lambda_{2} \\
& \sum_{u=1}^{2 n} x_{i u}^{4}=r 2^{t(k)}+2 a^{4}=\text { constant } \\
& =3(2 n) \lambda_{4} \\
& \sum_{u=1}^{2 n} x_{i u}^{2} x_{j u}^{2}=\lambda 2^{t(k)}=\text { constant } \\
& =2 n \lambda_{4}
\end{aligned}
$$

From (17) and (18) we get $\mathrm{a}^{4}=(3 \lambda-\mathrm{r}) 2^{\mathrm{t}(\mathrm{k})-1}$.

Substitute ' $a$ ' value in (16) and (17), we get the $\lambda_{2}$ and $\lambda_{4}$ values. The variance of the estimated response for a given ' $\mathrm{v}$ ' is tabulated for $\rho=-0.9$ (0.1) 0.9. 


\section{Case (ii): when $r=3 \lambda$}

The design points $\left[1-\left(\mathrm{v}, \mathrm{b}, \mathrm{r}, \mathrm{k}_{1}, \mathrm{k}_{2}, \ldots, \mathrm{k}_{\mathrm{p}}, \lambda\right)\right] 2^{\mathrm{t}(\mathrm{k})} \mathrm{U}\left(\mathrm{n}_{0}\right)$ will give a $\mathrm{v}$ dimensional SORD under tri-diagonal correlated structure of errors in $\mathrm{N}\left(=2 \mathrm{n}, \mathrm{n}=\mathrm{b} 2^{\mathrm{t}(\mathrm{k})}\right)$ design points.

Proof: For the design points generated from the PBD, simple symmetry conditions are true. Further we have

$$
\begin{aligned}
& \sum_{u=1}^{2 n} x_{i u}^{2}=r 2^{t(k)}=\text { constant } \\
& =2 n \lambda_{2} \\
& \sum_{u=1}^{2 n} x_{i u}^{4}=r 2^{t(k)}=\text { constant } \\
& =3(2 n) \lambda_{4}, \\
& \sum_{u=1}^{2 n} x_{i u}^{2} x_{j u}^{2}=\lambda 2^{t(k)}=\text { constant } \\
& =2 n \lambda_{4},
\end{aligned}
$$

From (3.5) and (3.6) we get $r=3 \lambda$.

From (19), (20) and (21) we get $\lambda_{2}, \lambda_{4}$ values. The variance of the estimated response for a given ' $\mathrm{v}$ ' is tabulated for $\rho=-0.9(0.1) 0.9$.

\section{Case (iii): Theorem (3.3) when $r>3 \lambda$}

The design points, $\left[1-\left(v, b, r, k_{1}, k_{2}, \ldots, k_{p}, \lambda\right)\right] 2^{t(k)} \cup(a, a, a, \ldots, a) 2^{t(v)} U$ $\left(\mathrm{n}_{0}\right)$ will give a v-dimensional SORD under tri-diagonal correlated structure of errors in $\mathrm{N}\left(=2 \mathrm{n}, \mathrm{n}=\mathrm{b} 2^{\mathrm{t}(\mathrm{k})}+2^{\mathrm{t}(\mathrm{v})}\right)$ design points, with $\mathrm{a}^{4}=$ $(\mathrm{r}-3 \lambda) 2^{\mathrm{t}(\mathrm{k})-\mathrm{t}(\mathrm{v})-1}$.

Proof: For the design points generated from the PBD, simple symmetry conditions are true. Further we have

$$
\begin{aligned}
& \sum_{u=1}^{2 n} x_{i u}^{2}=r 2^{t(k)}+2^{t(v)} a^{2}=\text { constant } \\
& =2 n \lambda_{2} \\
& \sum_{u=1}^{2 n} x_{i u}^{4}=r 2^{t(k)}+2^{t(v)} a^{4}=\text { constant } \\
& =3(2 n) \lambda_{4},
\end{aligned}
$$




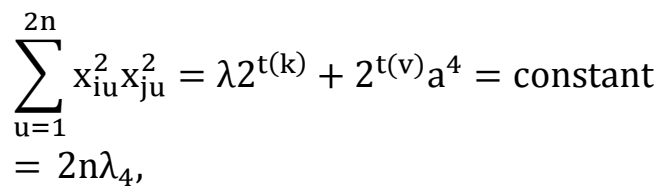

From (23) and (24) we get $\mathrm{a}^{4}=(\mathrm{r}-3 \lambda) 2^{\mathrm{t}(\mathrm{k})-\mathrm{t}(\mathrm{v})-1}$.

Substituting 'a' value in (23) and (24) and on simplification we get the $\lambda_{2}$ and $\lambda_{4}$. The variance of the estimated response for a given ' $v$ ' is tabulated for $\rho=-0.9(0.1) 0.9$.

Example: An empirical study of SORD for $v=8$ factors with the help of PBD with parameters $\left(v=8, b=15, r=6, k_{1}=4, k_{2}=3, k_{3}=2, \lambda=2\right)$ is given below. The design points, [1- $\left.\left(\mathrm{v}=8, \mathrm{~b}=15, \mathrm{r}=6, \mathrm{k}_{1}=4, \mathrm{k}_{2}=3, \mathrm{k}_{3}=2, \lambda=2\right)\right] 2^{4} \mathrm{U}$ $\left(\mathrm{n}_{0}=240\right)$ will give a 8 -dimensional SORD under tri-diagonal correlated structure of errors in $\mathrm{N}=480$ design points. Hence the design points are $\mathrm{N}=2 \mathrm{n}=480, \mathrm{n}=240$. Central points are added just below or above the noncentral design points. Hence we get 480 design points.

From (19), (20) and (21), we have

$$
\begin{aligned}
& \sum_{u=1}^{2 n} x_{i u}^{2}=96 \\
& =2 n \lambda_{2} \\
& \sum_{u=1}^{2 n} x_{i u}^{4}=96 \\
& =3(2 n) \lambda_{4}, \\
& \sum_{u=1}^{2 n} x_{i u}^{2} x_{j u}^{2}=32 \\
& =2 n \lambda_{4},
\end{aligned}
$$

The non -singularity condition (13) is also satisfied.

\section{A study of dependence of the variance function of the response at different design points}

Here, dependence of variance function of response at different design points for SORD under tri-diagonal correlated structure of errors using PBD with parameters $\left(\mathrm{v}=8, \mathrm{~b}=15, \mathrm{r}=6, \mathrm{k}_{1}=4, \mathrm{k}_{2}=3, \mathrm{k}_{3}=2, \lambda=2\right)$ with the tri-diagonal correlated coefficient ' $\rho$ ' and distance from centre ' $d$ ' is studied.

The variance function is given by 


$$
\begin{aligned}
& \mathrm{V}\left(\widehat{\mathrm{Y}}_{\mathrm{u}}\right) \\
& =\mathrm{V}\left(\hat{\mathrm{b}}_{0}\right)+\left[\mathrm{V}\left(\hat{\mathrm{b}}_{\mathrm{i}}\right)+2 \operatorname{Cov}\left(\hat{\mathrm{b}}_{0}, \hat{\mathrm{b}}_{\mathrm{ii}}\right)\right] \mathrm{d}^{2} \\
& +\mathrm{V}\left(\hat{\mathrm{b}}_{\mathrm{ii}}\right) \mathrm{d}^{4} \\
& \mathrm{~V}\left(\widehat{\mathrm{Y}}_{\mathrm{u}}\right)=\frac{0.6670(1+\rho) \sigma^{2}}{480[0.6670-0.3200(1-\rho)]} \\
& +\left[\frac{\sigma^{2}\left(1-\rho^{2}\right)}{96}+2\left(\frac{-0.2000 \sigma^{2}\left(1-\rho^{2}\right)}{480[0.6670-0.3200(1-\rho)]}\right)\right] \mathrm{d}^{2} \\
& \quad+\frac{\sigma^{2}\left(1-\rho^{2}\right)[0.6003-0.2800(1-\rho)]}{64.0320[0.6670-0.3200(1-\rho)]} \mathrm{d}^{4} \\
& \quad \mathrm{~V}\left(\widehat{\mathrm{Y}}_{\mathrm{u}}\right)=0.0024(\text { by taking } \mathrm{d}=0.1, \rho=-0.9 \text { and } \sigma=1) .
\end{aligned}
$$

For a given $\mathrm{v}$, the study of variance function of response at different design points for SORD under tri-diagonal correlated structure of errors using PBD for " $v=8$ factor" and distance from centre $\mathrm{d}$ for $\mathrm{d}=0.1(0.1) 1$ are tabulated.

In the first row of table-I, we calculate the variance of the estimated response for different factors of ' $v$ ' at ' $\rho=-0.9$ '.

In the first row of table-II, we study the dependence of variance function at different design points for $\mathrm{d}=0.1(0.1) 1$ at ' $\rho=-0.9$ '.

\section{An empirical study on SORD under tri-diagonal correlated structure of errors using SUBA with two unequal block sizes}

Following Raghavarao (1962, 1963) and Das (2003) methods of constructions of SORD and RSORD, an empirical study on SORD under tridiagonal correlated structure of errors using SUBA with two unequal block sizes is studied.

Let ( $\left.v, b, r, k_{1}, k_{2}, b_{1}, b_{2} \lambda\right)$ is an equi-replicated SUBA with two unequal block sizes, $\mathrm{k}=\sup \left[\mathrm{k}_{1}, \mathrm{k}_{2}\right]$ and $\mathrm{b}=\mathrm{b}_{1}+\mathrm{b}_{2}$. $2^{\mathrm{t}(\mathrm{k})}$ denotes a resolution $\mathrm{V}$ fractional factorial of $2^{\mathrm{k}}$ in \pm 1 levels, in which no interaction with less than five factors is confounded and $\mathrm{n}_{0}$ denote the number of central points.

Consider a SORD using SUBA with two unequal block sizes having ' $n$ ' noncentral design points. The set of ' $n$ '-non central design points are extended to $2 n$ design points by adding ' $n$ ' $\left(n_{0}=n\right)$ central points just below or above the ' $n$ ' non-central design points. Hence $2 \mathrm{n}$ be the total number of design points of the SORD under tri-diagonal correlated structure of errors using SUBA with two unequal block sizes. 
Case (i) : when $r<3 \lambda$

The design points, $\left[1-\left(v, b, r, k_{1}, k_{2}, b_{1}, b_{2} \lambda\right)\right] 2^{t(k)} \cup(a, 0,0, \ldots, 0) 2^{1} \cup$ $\left(\mathrm{n}_{0}\right), \quad \mathrm{k}=\sup \left[\mathrm{k}_{1}, \mathrm{k}_{2}\right]$ and $\mathrm{b}=\mathrm{b}_{1}+\mathrm{b}_{2}$ will give a $\mathrm{v}$-dimensional SORD under tri-diagonal correlated structure of errors in $\mathrm{N}=2 \mathrm{n}$ design points, with $a^{4}=(3 \lambda-r) 2^{t(k)-1}$.

Proof: follow by verifying the conditions of (2) to (5)

Case (ii): when $r=3 \lambda$

The design points $\left[1-\left(\mathrm{v}, \mathrm{b}, \mathrm{r}, \mathrm{k}_{1}, \mathrm{k}_{2}, \mathrm{~b}_{1}, \mathrm{~b}_{2} \lambda\right)\right] 2^{\mathrm{t}(\mathrm{k})} \mathrm{U}\left(\mathrm{n}_{0}\right), \mathrm{k}=\sup \left[\mathrm{k}_{1}, \mathrm{k}_{2}\right]$ and $\mathrm{b}=\mathrm{b}_{1}+\mathrm{b}_{2}$ will give a v-dimensional SORD under tri-diagonal correlated structure of errors in $\mathrm{N}=2 \mathrm{n}$ design points.

Proof: Proof follow by verifying the conditions of (2) to (5)

\section{Case (iii): when $r>3 \lambda$}

The design points, [1-(v, b, r, $\left.\left.\mathrm{k}_{1}, \mathrm{k}_{2}, \mathrm{~b}_{1}, \mathrm{~b}_{2} \lambda\right)\right] 2^{\mathrm{t}(\mathrm{k})} \cup(\mathrm{a}, \mathrm{a}, \mathrm{a}, \ldots, \mathrm{a}) 2^{\mathrm{t}(\mathrm{v})} \cup\left(\mathrm{n}_{0}\right)$, $\mathrm{k}=\sup \left[\mathrm{k}_{1}, \mathrm{k}_{2}\right]$ and $\mathrm{b}=\mathrm{b}_{1}+\mathrm{b}_{2}$ will give a v-dimensional SORD under tridiagonal correlated structure of errors in $\mathrm{N}=2 \mathrm{n}$ design points, with $\mathrm{a}^{4}=$ $(\mathrm{r}-3 \lambda) 2^{\mathrm{t}(\mathrm{k})-\mathrm{t}(\mathrm{v})-1}$.

Proof: follow by verifying the conditions of (2) to (5).

Example: An empirical study of SORD for $v=8$ factors with the help of SUBA with two unequal block sizes with parameters $\left(\mathrm{v}=8, \mathrm{~b}=12, \mathrm{r}=4, \mathrm{k}_{1}=2\right.$, $\left.\mathrm{k}_{2}=3, \mathrm{~b}_{1}=4, \mathrm{~b}_{2}=8, \lambda=1\right)$ is given below. The design points, $[1-(\mathrm{v}=8, \mathrm{~b}=12$, $\left.\left.\mathrm{r}=4, \mathrm{k}_{1}=2, \mathrm{k}_{2}=3, \mathrm{~b}_{1}=4, \mathrm{~b}_{2}=8, \lambda=1\right)\right] 2^{3} \cup( \pm \mathrm{a}, \pm \mathrm{a}, \ldots, \pm \mathrm{a}) 2^{6} \cup\left(\mathrm{n}_{0}=160\right)$. Hence the design points are $N=2 n=320, n=160$. Central points are added just below or above the non-central design points then we get 160 design points.

From (22), (23) and (24), we have

$$
\begin{aligned}
& \sum_{u=1}^{2 n} x_{i u}^{2}=32+64 a^{2} \\
& =2 n \lambda_{2}, \\
& \sum_{u=1}^{2 n} x_{i u}^{4}=32+64 a^{4} \\
& =3(2 n) \lambda_{4}, \\
& \sum_{u=1}^{2 n} x_{i u}^{2} x_{j u}^{2}=8+64 a^{4} \\
& =2 n \lambda_{4},
\end{aligned}
$$


From (31) and (32), we get a $=0.5$. The non-singularity condition (13) is also satisfied.

\section{A study of dependence of the variance function of the response at different design points}

Here, dependence of variance function of response at different design points for SORD under tri-diagonal correlated structure of errors using SUBA with two unequal block sizes with parameters $\left(\mathrm{v}=8, \mathrm{~b}=12, \mathrm{r}=4, \mathrm{k}_{1}=2, \mathrm{k}_{2}=3, \mathrm{~b}_{1}=4\right.$, $\mathrm{b}_{2}=8, \lambda=1$ ) with the tri-diagonal correlated coefficient ' $\rho$ ' and distance from centre ' $\mathrm{d}$ ' is studied.

The variance function is given by

$$
\begin{aligned}
& \mathrm{V}\left(\widehat{\mathrm{Y}}_{\mathrm{u}}\right) \\
& =\mathrm{V}\left(\widehat{\mathrm{b}}_{0}\right)+\left[\mathrm{V}\left(\widehat{\mathrm{b}}_{\mathrm{i}}\right)+2 \operatorname{Cov}\left(\hat{\mathrm{b}}_{0}, \hat{\mathrm{b}}_{\mathrm{ii}}\right)\right] \mathrm{d}^{2} \\
& +\mathrm{V}\left(\hat{\mathrm{b}}_{\mathrm{ii}}\right) \mathrm{d}^{4} \\
& \mathrm{~V}\left(\widehat{\mathrm{Y}}_{\mathrm{u}}\right)=\frac{0.3750(1+\rho) \sigma^{2}}{320[0.3750-0.1800(1-\rho)]} \\
& +\left[\frac{\sigma^{2}\left(1-\rho^{2}\right)}{48}+2\left(\frac{-0.1500 \sigma^{2}\left(1-\rho^{2}\right)}{320[0.3750-0.1800(1-\rho)]}\right)\right] \mathrm{d}^{2} \\
& +\frac{\sigma^{2}\left(1-\rho^{2}\right)[0.3375-0.1575(1-\rho)]}{24[0.3750-0.1800(1-\rho)]} \mathrm{d}^{4} \\
& \mathrm{~V}\left(\widehat{\mathrm{Y}}_{\mathrm{u}}\right)=0.0034(\text { by taking } \mathrm{d}=0.1, \rho=-0.9 \text { and } \sigma=1) .
\end{aligned}
$$

For a given $v$, the study of variance function of response at different design points for SORD under tri-diagonal correlated structure of errors using SUBA with two unequal block sizes for " $\mathrm{v}=8$ factor" and distance from centre $\mathrm{d}$ for $\mathrm{d}=0.1(0.1) 1$ are given in table-III and IV.

In the first row of table-III, we calculate the variance of the estimated response for different factors of ' $v$ ' at ' $\rho=-0.9$ '.

In the first row of table-IV, we study the dependence of variance function at different design points for $\mathrm{d}=0.1(0.1) 1$ at ' $\rho=-0.9$ '.

Conclusion: We may point out here that the SORD under tri-diagonal correlated structure of errors using SUBA with two unequal block sizes with parameters $\left(\mathrm{v}=8, \mathrm{~b}=12, \mathrm{r}=4, \mathrm{k}_{1}=2, \mathrm{k}_{2}=3, \mathrm{~b}_{1}=4, \mathrm{~b}_{2}=8, \lambda=1\right)$ has 320 design points for 8 - factors where as the corresponding SORD under tri-diagonal correlated structure of errors using BIBD with 
parameters $(\mathrm{v}=8, \mathrm{~b}=28, \mathrm{r}=7, \mathrm{k}=2, \lambda=1)$ needs 352 design points and SORD under tri-diagonal correlated structure of errors using PBD with parameters $\left(\mathrm{v}=8, \mathrm{~b}=15, \mathrm{r}=6, \mathrm{k}_{1}=4, \mathrm{k}_{2}=3, \mathrm{k}_{3}=2, \lambda=2\right)$ needs 480 design points. Therefore, this method gives less number of design points than the corresponding SORD under tri-diagonal structure of errors using BIBD and PBD.

\section{Results and Conclusions:}

From the table-I and table-II we observed that,

(i) $\quad \mathrm{V}(\widehat{\mathrm{Y}})$ is slightly increasing for different values of $\rho$ is increasing.

(ii) $\mathrm{d}=0.1(0.1) 1.0$, for given $\mathrm{v}, \rho ; \mathrm{V}(\widehat{\mathrm{Y}})$ is slightly increasing.

(iii) The above two structures sometimes gives less number of design points when compared with other designs.

Here we give the tables for $\mathrm{v}=8$ factor of SORD under tridiagonal correlated error structure using PBD and SORD under tri-diagonal correlated error structure using SUBA with two unequal block sizes are given in the appendix. Remaining all tables are present in the following Hyperlink.(www.satishmaster.page.tl)

\section{References}

1. G.E.P. Box, and J.S. Hunter, (1957). 'Multifactor experimental designs for exploring response surfaces, Annals of Mathematical Statistics, 28, 195-241.

2. M. N. Das, and V. L. Narasimham, (1962). Construction of rotatable designs through balanced incomplete block designs, Annals of Mathematical Statistics, 33, 1421-1439.

3. R.N. Das, (1997). Robust second order rotatable designs (Part -I). Calcutta Statistical Association Bulletin, 47, 199-214.

4. R.N. Das, (1999). Robust second order rotatable designs (Part -II). Calcutta Statistical Association Bulletin, 49, 65-78. 
5. R. N, Das. (2003). Robust second order rotatable designs: Part -III. Journal of the Indian Society of Agricultural Statistics, 56, 117130.

6. R. N, Das. (2004). Construction and analysis of robust second order rotatable designs. Journal of Statistical Theory and Applications, 3, 325-343.

7.R.N. Panda, and R.N. Das, (1994). First order rotatable designs with correlated errors. Calcutta Statistical Association Bulletin, 44, 83-101.

8. D. Raghavarao, (1971). Constructions and combinatorial problems in design of experiments, John Wiley, New York.

9. K. Rajyalakshmi, and B. Re. Victorbabu, (2014a). An empirical study of second order rotatable designs under tri-diagonal correlated structure of errors using central composite designs. Journal of Statistics: Advances in theory and applications, 11, 2014.

10. K. Rajyalakshmi, and B. Re. Victorbabu, (2014b). An empirical study of second order rotatable designs under tri-diagonal correlated structure of errors using balanced incomplete block designs. Submitted for the possible publication.

\section{$\underline{\text { Results for all factors }}$}


Table : I

Variance of the estimated response for the $v=8$ factor under tri-diagonal correlated structure of errors using PBD

\begin{tabular}{|c|c|}
\hline \multirow[t]{2}{*}{$\rho$} & $\mathbf{V}\left(\widehat{\mathbf{Y}}_{\mathbf{u}}\right)$ \\
\hline & $\begin{array}{c}\left(v=8, b=15, r=6, k_{1}=4, k_{2}=3, k_{3}=2, \lambda=2\right) \\
n=240, N=2 n=480\end{array}$ \\
\hline-0.9 & $0.0024 \sigma^{2}-0.0007 \sigma^{2} \mathrm{~d}^{2}+0.0034 \sigma^{2} \mathrm{~d}^{4}$ \\
\hline-0.8 & $0.0031 \sigma^{2}+0.0004 \sigma^{2} \mathrm{~d}^{2}+0.0060 \sigma^{2} \mathrm{~d}^{4}$ \\
\hline-0.7 & $0.0034 \sigma^{2}+0.0018 \sigma^{2} \mathrm{~d}^{2}+0.0081 \sigma^{2} \mathrm{~d}^{4}$ \\
\hline-0.6 & $0.0036 \sigma^{2}+0.0032 \sigma^{2} \mathrm{~d}^{2}+0.0098 \sigma^{2} \mathrm{~d}^{4}$ \\
\hline-0.5 & $0.0037 \sigma^{2}+0.0045 \sigma^{2} \mathrm{~d}^{2}+0.0113 \sigma^{2} \mathrm{~d}^{4}$ \\
\hline-0.4 & $0.0038 \sigma^{2}+0.0055 \sigma^{2} \mathrm{~d}^{2}+0.0125 \sigma^{2} \mathrm{~d}^{4}$ \\
\hline-0.3 & $0.0039 \sigma^{2}+0.0065 \sigma^{2} d^{2}+0.0134 \sigma^{2} d^{4}$ \\
\hline-0.2 & $0.0039 \sigma^{2}+0.0072 \sigma^{2} \mathrm{~d}^{2}+0.0140 \sigma^{2} \mathrm{~d}^{4}$ \\
\hline-0.1 & $0.0040 \sigma^{2}+0.0070 \sigma^{2} \mathrm{~d}^{2}+0.0144 \sigma^{2} \mathrm{~d}^{4}$ \\
\hline 0 & $0.0040 \sigma^{2}+0.0080 \sigma^{2} \mathrm{~d}^{2}+0.0144 \sigma^{2} \mathrm{~d}^{4}$ \\
\hline 0.1 & $0.0040 \sigma^{2}+0.0081 \sigma^{2} \mathrm{~d}^{2}+0.0142 \sigma^{2} \mathrm{~d}^{4}$ \\
\hline 0.2 & $0.0041 \sigma^{2}+0.0081 \sigma^{2} \mathrm{~d}^{2}+0.0137 \sigma^{2} \mathrm{~d}^{4}$ \\
\hline 0.3 & $0.0041 \sigma^{2}+0.0078 \sigma^{2} \mathrm{~d}^{2}+0.0130 \sigma^{2} \mathrm{~d}^{4}$ \\
\hline 0.4 & $0.0041 \sigma^{2}+0.0073 \sigma^{2} \mathrm{~d}^{2}+0.0119 \sigma^{2} \mathrm{~d}^{4}$ \\
\hline 0.5 & $0.0041 \sigma^{2}+0.0066 \sigma^{2} \mathrm{~d}^{2}+0.0106 \sigma^{2} \mathrm{~d}^{4}$ \\
\hline 0.6 & $0.0041 \sigma^{2}+0.0057 \sigma^{2} \mathrm{~d}^{2}+0.0091 \sigma^{2} \mathrm{~d}^{4}$ \\
\hline 0.7 & $0.0041 \sigma^{2}+0.0046 \sigma^{2} d^{2}+0.0072 \sigma^{2} d^{4}$ \\
\hline 0.8 & $0.0041 \sigma^{2}+0.0033 \sigma^{2} \mathrm{~d}^{2}+0.0051 \sigma^{2} \mathrm{~d}^{4}$ \\
\hline 0.9 & $0.0042 \sigma^{2}+0.0017 \sigma^{2} \mathrm{~d}^{2}+0.0027 \sigma^{2} \mathrm{~d}^{4}$ \\
\hline
\end{tabular}


An Empirical Study of Second Order Rotatable Designs

TABLE-II: Study of the dependence of the variance function at different design points $\left(v=8, b=15, r=6, k_{1}=4, k_{2}=3, k_{3}=2, \lambda=2\right)$

\begin{tabular}{|c|c|c|c|c|c|c|c|c|c|c|}
\hline & $=0.1^{\mathrm{d}}$ & $=0.2^{\mathrm{d}}$ & $=0.3^{\mathrm{d}}$ & $=0.4^{\mathrm{d}}$ & $=0.5^{\mathrm{d}}$ & $=0.6^{\mathrm{d}}$ & $=0.7^{\mathrm{d}}$ & $=0.8^{\mathrm{d}}$ & $=0.9^{\mathrm{d}}$ & $=1^{d}$ \\
\hline 0.9 & $.0024^{0}$ & $.0024^{0}$ & $.0024^{0}$ & $.0024^{0}$ & \begin{tabular}{|c|}
0 \\
$.0024^{0}$
\end{tabular} & $.0026^{0}$ & $.0029^{0}$ & $.0033^{0}$ & $.0041^{0}$ & $.0051^{0}$ \\
\hline 0.8 & $.0031^{0}$ & $.0031^{0}$ & $.0032^{0}$ & $.0033^{0}$ & $.0036^{0}$ & $.0040^{0}$ & $.0047^{0}$ & $.0058^{0}$ & $.0074^{0}$ & $.0095^{0}$ \\
\hline 0.7 & $.0034^{0}$ & $.0035^{0}$ & $.0036^{0}$ & $\begin{array}{c}0 \\
.0039 \\
\end{array}$ & $.0044^{0}$ & $.0051^{0}$ & $.0062^{0}$ & $\begin{array}{r}0 \\
.0079^{0} \\
\end{array}$ & $\begin{array}{c}0 \\
.0102^{0} \\
\end{array}$ & $.0133^{0}$ \\
\hline 0.6 & $.0036^{0}$ & $.0037^{0}$ & $.0040^{0}$ & $.0044^{0}$ & $.0050^{0}$ & $.0060^{0}$ & $.0075^{0}$ & $.0097^{0}$ & $.0126^{0}$ & $.0166^{0}$ \\
\hline 0.5 & $.0037^{0}$ & $.0039^{0}$ & $.0042^{0}$ & $.0047^{0}$ & $.0055^{0}$ & $.0068^{0}$ & $.0086^{0}$ & $.0112^{0}$ & $.0148^{0}$ & $.0195^{0}$ \\
\hline 0.4 & \begin{tabular}{|c|}
0 \\
$.0039^{0}$ \\
\end{tabular} & $.0040^{0}$ & $.0044^{0}$ & $\begin{array}{c}0 \\
.0050^{0} \\
\end{array}$ & $\begin{array}{c}0 \\
.0060^{0} \\
\end{array}$ & $.0074^{0}$ & $.0095^{0}$ & $.0124^{0}$ & \begin{tabular}{|c|}
0 \\
$.0165^{0}$ \\
\end{tabular} & ${ }^{0}{ }^{0}$ \\
\hline 0.3 &.$^{0} .0040^{0}$ & $.0042^{0}$ & $.0046^{0}$ & $.0053^{0}$ & $.0064^{0}$ & $.0080^{0}$ & $.0103^{0}$ & $.0135^{0}$ & $.0180^{0}$ & \\
\hline 0.2 & $.0040^{0}$ & $.0042^{0}$ & $.0047^{0}$ & $.0054^{0}$ & $.0066^{0}$ & $.0083^{0}$ & $.0108^{0}$ & $.0142^{0}$ & $\begin{array}{c}0 \\
.0189^{0} \\
\end{array}$ & \\
\hline 0.1 & $.0041^{0}$ & $.0043^{0}$ & $.0048^{0}$ & $.0056^{0}$ & $.0068^{0}$ & $.0086^{0}$ & $.0112^{0}$ & $.0148^{0}$ & $\begin{array}{r}0 \\
.0197^{0} \\
\end{array}$ & $\begin{array}{l}0 \\
.0261 \\
\end{array}$ \\
\hline & $.0041^{0}$ & $.0043^{0}$ & $.0048^{0}$ & $.0056^{0}$ & $.0069^{0}$ & $.0087^{0}$ & $.0114^{0}$ & $.015^{0}$ & \begin{tabular}{|c|}
$0199^{0}$ \\
\end{tabular} & $\begin{array}{l}0 \\
.0264\end{array}$ \\
\hline .1 & $.0041^{0}$ & $.0043^{0}$ & $.0048^{0}$ & $\begin{array}{r}0 \\
.0057^{0}\end{array}$ & $.0069^{0}$ & $.0088^{0}$ & $.0114^{0}$ & & $.0199^{0}$ & \\
\hline .2 & $.0042^{0}$ & $.0044^{0}$ & $.0049^{0}$ & $\begin{array}{r}0 \\
.0057^{0} \\
\end{array}$ & $.0070^{0}$ & $.0088^{0}$ & $.0114^{0}$ & $.0149^{0}$ & $.0196^{0}$ & $\begin{array}{l}0 \\
.0259^{0} \\
\end{array}$ \\
\hline .3 & $.0042^{0}$ & $.0044^{0}$ & $.0049^{0}$ & $\begin{array}{r}0 \\
.0057^{0} \\
\end{array}$ & $\begin{array}{r}0 \\
.0069^{0} \\
\end{array}$ & $.0086^{0}$ & $.0110^{0}$ & $.0144^{0}$ & $\begin{array}{c}0 \\
.0189^{0} \\
\end{array}$ & $\begin{array}{l}{ }^{0} \\
.0249 \\
\end{array}$ \\
\hline .4 & \begin{tabular}{|c|}
0 \\
$.0042^{0}$
\end{tabular} & $.0044^{0}$ & \begin{tabular}{|c|}
0 \\
$.0049^{0}$
\end{tabular} & $\begin{array}{c}0 \\
.0056^{0} \\
\end{array}$ & $\begin{array}{r}0 \\
.0067^{0} \\
\end{array}$ & $.0083^{0}$ & \begin{tabular}{|c|}
0 \\
\end{tabular} & $.0136^{0}$ &.$^{0}{ }^{0}$ & $.0233^{0}$ \\
\hline .5 & $.0042^{0}$ & $.0044^{0}$ & $\begin{array}{c}0 \\
.0048^{0} \\
\end{array}$ & $.0054^{0}$ & $.0064^{0}$ & $.0078^{0}$ & $\begin{array}{c}0 \\
.0099 \\
\end{array}$ & $\begin{array}{r}0 \\
.0127^{0}\end{array}$ & $.0164^{0}$ & $.0213^{0}$ \\
\hline .6 & $.0042^{0}$ & $.0043^{0}$ & $.0047^{0}$ & $.0052^{0}$ & $.0061^{0}$ & $.0073^{0}$ & $.0091^{0}$ & $.0115^{0}$ &.$^{0}{ }^{0} .0147^{2}$ & $.0189^{0}$ \\
\hline .7 & $\begin{array}{r}0 \\
.0041^{0}\end{array}$ & $.0043^{0}$ & $.0046^{0}$ & $.005^{0}$ & $\begin{array}{r}0 \\
.0057^{0} \\
\end{array}$ & $\begin{array}{r}0 \\
.0067^{0}\end{array}$ & $\begin{array}{r}0 \\
.0081^{0}\end{array}$ & $.0100^{0}$ & $.0125^{0}$ & $\begin{array}{l}0159^{0} \\
\end{array}$ \\
\hline .8 & $.0041^{0}$ & $.0042^{0}$ & $.0044^{0}$ & $.0048^{0}$ & $.0052^{0}$ & $\begin{array}{c}0 \\
.0059^{0} \\
\end{array}$ & $.0069^{0}$ & $.0083^{0}$ & $.0101^{0}$ & $.0125^{0}$ \\
\hline .9 & $.0042^{0}$ & $.0043^{0}$ & $.0044^{0}$ & $.0045^{0}$ & $.0048^{0}$ & $.0052^{0}$ & $.0057^{0}$ & $.0064^{0}$ & $.0073^{0}$ & $.0086^{0}$ \\
\hline
\end{tabular}


Table : III

Variance of the estimated response for $v=8$ factor under tridiagonal correlated structure of errors using SUBA with two unequal block sizes

\begin{tabular}{|c|c|}
\hline \multirow{3}{*}{$\boldsymbol{\rho}$} & $\mathbf{V}\left(\widehat{\mathbf{Y}}_{\mathbf{u}}\right)$ \\
\hline & $\begin{array}{c}\left(v=8, b=12, r=4, k_{1}=2, k_{2}=3, b_{1}=4, b_{2}=8,\right. \\
\lambda=1)\end{array}$ \\
\hline & $N=2 n=320, n=160$ \\
\hline-0.9 & $0.0036 \sigma^{2}-0.0014 \sigma^{2} d^{2}+0.0092 \sigma^{4} d^{4}$ \\
\hline-0.8 & $0.0046 \sigma^{2}+0.0009 \sigma^{2} d^{2}+0.0159 \sigma^{4} d^{4}$ \\
\hline-0.7 & $0.0051 \sigma^{2}+0.0037 \sigma^{2} d^{2}+0.0215 \sigma^{4} d^{4}$ \\
\hline-0.6 & $0.0054 \sigma^{2}+0.0064 \sigma^{2} \mathrm{~d}^{2}+0.0262 \sigma^{4} \mathrm{~d}^{4}$ \\
\hline-0.5 & $0.0056 \sigma^{2}+0.0089 \sigma^{2} d^{2}+0.0301 \sigma^{4} d^{4}$ \\
\hline-0.4 & $0.0057 \sigma^{2}+0.0111 \sigma^{2} \mathrm{~d}^{2}+0.0333 \sigma^{4} \mathrm{~d}^{4}$ \\
\hline-0.3 & $0.0058 \sigma^{2}+0.0129 \sigma^{2} d^{2}+0.0357 \sigma^{4} d^{4}$ \\
\hline-0.2 & $0.0059 \sigma^{2}+0.0143 \sigma^{2} \mathrm{~d}^{2}+0.0374 \sigma^{4} \mathrm{~d}^{4}$ \\
\hline-0.1 & $0.0060 \sigma^{2}+0.0154 \sigma^{2} \mathrm{~d}^{2}+0.0383 \sigma^{4} \mathrm{~d}^{4}$ \\
\hline 0 & $0.0060 \sigma^{2}+0.0160 \sigma^{2} d^{2}+0.0385 \sigma^{4} d^{4}$ \\
\hline 0.1 & $0.0061 \sigma^{2}+0.0163 \sigma^{2} \mathrm{~d}^{2}+0.0379 \sigma^{4} \mathrm{~d}^{4}$ \\
\hline 0.2 & $0.0061 \sigma^{2}+0.0161 \sigma^{2} \mathrm{~d}^{2}+0.0366 \sigma^{4} \mathrm{~d}^{4}$ \\
\hline 0.3 & $0.0061 \sigma^{2}+0.0155 \sigma^{2} \mathrm{~d}^{2}+0.0346 \sigma^{4} \mathrm{~d}^{4}$ \\
\hline 0.4 & $0.0061 \sigma^{2}+0.0146 \sigma^{2} \mathrm{~d}^{2}+0.0319 \sigma^{4} \mathrm{~d}^{4}$ \\
\hline 0.5 & $0.0062 \sigma^{2}+0.0132 \sigma^{2} \mathrm{~d}^{2}+0.0284 \sigma^{4} \mathrm{~d}^{4}$ \\
\hline 0.6 & $0.0062 \sigma^{2}+0.0114 \sigma^{2} \mathrm{~d}^{2}+0.0242 \sigma^{4} \mathrm{~d}^{4}$ \\
\hline 0.7 & $0.0062 \sigma^{2}+0.0091 \sigma^{2} d^{2}+0.0192 \sigma^{4} d^{4}$ \\
\hline 0.8 & $0.0062 \sigma^{2}+0.0065 \sigma^{2} d^{2}+0.0135 \sigma^{4} d^{4}$ \\
\hline 0.9 & $0.0062 \sigma^{2}+0.0035 \sigma^{2} \mathrm{~d}^{2}+0.0071 \sigma^{4} \mathrm{~d}^{4}$ \\
\hline
\end{tabular}


An Empirical Study of Second Order Rotatable Designs

TABLE-IV: Study of the dependence of the variance function at different design points

$$
\left(v=8, b=12, r=4, k_{1}=2, k_{2}=3, b_{1}=4, b_{2}=8, \lambda=1\right)
$$

\begin{tabular}{|c|c|c|c|c|c|c|c|c|c|c|}
\hline & $=0.1^{d}$ & $=0.2^{\mathrm{d}}$ & $=0.3^{\mathrm{d}}$ & $=0.4^{\mathrm{d}}$ & $=0.5^{\mathrm{d}}$ & $=0.6^{\mathrm{d}}$ & $=0.7^{\mathrm{d}}$ & $=0.8^{d}$ & $=0.9^{\mathrm{d}}$ & $=1$ \\
\hline 0.9 & $.0036^{0}$ & $.0036^{0}$ & $.0036^{0}$ & $.0036^{0}$ & ${ }^{0} .0038^{0}$ & ${ }^{0}{ }^{0}$ & $.0051^{0}$ & $\begin{array}{r}0 \\
.0065^{0}\end{array}$ & $.0085^{0}$ & $.0114^{0}$ \\
\hline $\mathbf{0 . 8}$ & $.0046^{0}$ & $\begin{array}{r}0 \\
0 \\
\end{array}$ & $\begin{array}{l}0 \\
.0048^{0}\end{array}$ & $.0051^{0}$ & ${ }^{0}{ }^{0}$ & $.007^{0}$ &.$^{0}{ }^{0}$ & $\begin{array}{r}0 \\
0 \\
.0117^{0}\end{array}$ & $\begin{array}{r}0 \\
.0157^{0}\end{array}$ & ${ }^{0}{ }^{0}$ \\
\hline 0.7 & $\begin{array}{r}0 \\
.0051\end{array}$ & $.0053^{0}$ & $\begin{array}{r} \\
.0056^{0}\end{array}$ & $.0062^{0}$ & $.0074^{0}$ & $\begin{array}{c}0 \\
.0092^{0}\end{array}$ & $.0121^{0}$ & $.0163^{0}$ & $.0222^{0}$ & $.0303^{0}$ \\
\hline 0.6 & $.0055^{0}$ & $\begin{array}{r}0 \\
0\end{array}$ & $.0062^{0}$ & $.0071^{0}$ & $.0086^{0}$ & $.0111^{0}$ & $.0148^{0}$ & $.0203^{0}$ & ${ }^{0}{ }^{0}$ & $\begin{array}{r}0 \\
.0380\end{array}$ \\
\hline 0.5 & $.0057^{0}$ & $.006^{0}$ & $.0067^{0}$ & $.0078^{0}$ & $\begin{array}{r}0 \\
0\end{array}$ & $.0127^{0}$ & $.0172^{0}$ & $.0236^{0}$ & $.0326^{0}$ & $.0446^{0}$ \\
\hline 0.4 & $\begin{array}{r}0 \\
.0058^{0}\end{array}$ & $.0062^{0}$ & $\begin{array}{r}0 \\
.0070^{0}\end{array}$ & $.0083^{0}$ & $.0106^{0}$ & $.014^{0}$ & $.0191^{0}$ & $\begin{array}{r}0 \\
.0264^{0}\end{array}$ & $.0365^{0}$ & ${ }^{0}{ }^{0}$ \\
\hline 0.3 & ${ }^{0}{ }^{0}$ & ${ }^{0}{ }^{0}$ & $.0073^{0}$ & $.0088^{0}$ & $.0113^{0}$ & $.0151^{0}$ & $.0207^{0}$ & $\begin{array}{r}0 \\
.0287^{0}\end{array}$ & ${ }^{0}{ }^{0} .0397^{1}$ & $.0544^{0}$ \\
\hline 0.2 & $.006^{0}$ & $.0065^{0}$ & ${ }^{0}{ }^{0}$ & $.0092^{0}$ & $.0118^{0}$ & $\begin{array}{c}0 \\
.0159^{0}\end{array}$ & $.0219^{0}$ & $.0304^{0}$ & $.0421^{0}$ & $.0576^{0}$ \\
\hline 0.1 & $.0062^{0}$ & $\begin{array}{r}0 \\
.0067^{0}\end{array}$ & $\begin{array}{r}0 \\
.0077^{0}\end{array}$ & $.0094^{0}$ & $.0122^{0}$ & $\begin{array}{r}0 \\
.0165^{0}\end{array}$ & $\begin{array}{l}0 \\
.0227^{0}\end{array}$ & $.0315^{0}$ & $.0436^{0}$ & $\begin{array}{r}0 \\
.0597\end{array}$ \\
\hline & $.0062^{0}$ & $\begin{array}{r}0 \\
.0067\end{array}$ & $.0078^{0}$ & $.0096^{0}$ & $.0124^{0}$ & $\begin{array}{c}0 \\
.0168^{0}\end{array}$ & ${ }^{0}{ }^{0}$ & $\begin{array}{l}0 \\
.0320\end{array}$ & $.0442^{0}$ & $.0605^{0}$ \\
\hline .1 & $.0063^{0}$ & $.0068^{0}$ & $\begin{array}{c}0 \\
.0079^{0}\end{array}$ & $.0097^{0}$ & $.0125^{0}$ & $.0169^{0}$ & $.0232^{0}$ & .0320 & $.0441^{0}$ & $.0603^{0}$ \\
\hline .2 & ${ }^{0}{ }^{0}$ & ${ }^{0}{ }^{0}$ & $\begin{array}{r}0 \\
.0079\end{array}$ & ${ }^{0}{ }^{0}$ & $.0124^{0}$ & $.0166^{0}$ & $\begin{array}{r}0 \\
.0228^{\circ}\end{array}$ & $\begin{array}{r}0 \\
.0314^{0}\end{array}$ & $.0432^{0}$ & $\begin{array}{l}0 \\
.0588^{0}\end{array}$ \\
\hline .3 & $.0063^{0}$ & $\begin{array}{r}0 \\
.0068\end{array}$ & $\begin{array}{r}0 \\
.0078^{0}\end{array}$ & $.0095^{0}$ & $.0121^{0}$ & $.0162^{0}$ & $\begin{array}{l}0 \\
.0220\end{array}$ & $\begin{array}{r}0 \\
0 \\
.0302\end{array}$ & $\begin{array}{c}0 \\
.0414^{0}\end{array}$ & $\begin{array}{r}0 \\
.0562^{0}\end{array}$ \\
\hline .4 & $.0062^{0}$ & $\begin{array}{r}0 \\
.0067\end{array}$ & $\begin{array}{r}0 \\
.0077^{2}\end{array}$ & $.0092^{0}$ & $.0117^{0}$ & $.0155^{0}$ & $.0209^{0}$ & $.0285^{0}$ & $.0388^{0}$ & $.0526^{0}$ \\
\hline .5 & $.0063^{0}$ & $.0068^{0}$ & $.0076^{0}$ & $.009^{0}$ & $.0113^{0}$ & $.0146^{0}$ & $.0195^{0}$ & $.0263^{0}$ & $.0355^{0}$ & $.0478^{0}$ \\
\hline .6 & $.0063^{0}$ & $\begin{array}{r}0 \\
.0067^{0}\end{array}$ & $\begin{array}{r}0 \\
.0074^{0}\end{array}$ & $.0086^{0}$ & $.0106^{0}$ & $.0134^{0}$ & $.0176^{0}$ & $.0234^{0}$ & $.0313^{0}$ & $.0418^{0}$ \\
\hline .7 & $.0063^{0}$ & $.0066^{0}$ & $.0072^{0}$ & $.0082^{0}$ & $.0097^{0}$ & $.012^{0}$ & $.0153^{0}$ & $\begin{array}{c}0 \\
0\end{array}$ & $.0262^{0}$ & $.0345^{0}$ \\
\hline .8 & $.0063^{0}$ & $.0065^{0}$ & $\begin{array}{r}0 \\
.0069^{0}\end{array}$ & $.0076^{0}$ & $.0087^{0}$ & $.0103^{0}$ & $.0126^{0}$ & $.0159^{0}$ & $.0203^{0}$ & $.0262^{0}$ \\
\hline .9 & $.0062^{0}$ & $.0063^{0}$ & $.0066^{0}$ & $.0069^{0}$ & $.0075^{0}$ & $.0084^{0}$ & $.0096^{0}$ & $.0113^{0}$ & $.0137^{0}$ & $.0168^{0}$ \\
\hline
\end{tabular}

